\title{
JOSÉ AGUSTIN GOYTISOLO Y SU GENERACIÓN: ESTILO DE POESÍA Y ESTILO DE RECITADO
}

\author{
JOSÉ AGUSTIN GOYTISOLO AND \\ HIS GENERATION: POETRY STYLE \\ AND RECITATION STYLE
}

\author{
Dolors Poch Olivé \\ Universitat Autònoma de Barcelona
}

Resumen: Este trabajo tiene como objetivo estudiar la forma en la que José Agustín Goytisolo y otros dos poetas de su generación, Jaime Gil de Biedma y Ángel González, recitan sus propios poemas. Como se verá, los tres poetas comparten un estilo cercano al habla coloquial, como así lo reclama el carácter de sus composiciones, pero presentan estrategias distintas a la hora de poner de relieve las características de los sonidos que constituyen el poema y, sobre todo, los rasgos del ritmo de los mismos. El artículo, elaborado desde la perspectiva de estudio de la Fonética experimental, propone, además, una metodología para analizar estas cuestiones que permite establecer, cuantitativamente, las diferencias entre los tres estilos de recitación y que es aplicable a otros estudios que se propongan los mismos objetivos.

Palabras clave: Poesía; recitar; ritmo; José Agustín Goytisolo; Jaime Gil de Biedma; Ángel González.

Aвstract: This paper aims to study how José Agustín Goytisolo and two other poets of his generation, Jaime Gil de Biedma and Ángel González, recite their own poems. As it will be shown, the three poets share a style close to colloquial speech, as the characteristics of their compositions demand, but they show different strategies when it comes to highlighting the characteristics of the sounds that make up the poem and, above all, the features of their rhythm. The paper, written from the perspective of the study of experimental Phonetics, also proposes a methodology to analyze these matters that allows to establish, quantitatively, the differences between the three styles of recitation and that is applicable to other studies that propose the same objectives.

Key words: Poetry; recite; rhythm; José Agustín Goytisolo; Jaime Gil de Biedma; Ángel González. 


\section{INTRODUCCIÓN}

En el siglo XXI, el acto de leer se concibe como una operación que consiste en «[p]asar la vista por lo escrito o impreso comprendiendo la significación de los caracteres empleados", como lo indica el DRAE (2014) en la primera acepción del vocablo «Leer».Y en el mismo Diccionario, bajo la entrada «Lectura» figura, como primera acepción, «[o]peración de leer». A nadie sorprende esta definición que parece una obviedad, pero esta imagen contemporánea de la lectura es, en realidad, muy reciente desde el punto de vista histórico, pues durante muchos siglos el acto de leer no era silencioso.

Margit Frenk (1997), en su excelente ensayo titulado Entre la voz y el silencio, traza el itinerario histórico de la lectura, que solía ser en voz alta hasta que, en el siglo XIX, se impuso su forma actual, la lectura silenciosa. Así, por ejemplo, señala la autora que San Agustín refiere en sus escritos que en ocasiones San Ambrosio, en público, practicaba una extraña costumbre: "Cuando leía sus ojos se deslizaban sobre las páginas y su corazón buscaba el sentido, pero su voz y su lengua no se movían» (Frenk, 1997: 73). San Ambrosio solamente se comportaba así en público porque, en caso contrario, «los que por ventura lo escucharan empezarían a proponerle dudas sobre cualquier pasaje oscuro» (Frenk, 1997: 73). En privado, sigue refiriendo San Agustín, leía de la forma habitual en la época, en voz baja: «Más de una vez entré a su cuarto y siempre me sucedió encontrarlo leyendo para sí y en voz baja» (Frenk, 1997: 73).

Cervantes, en el Quijote, refleja también esta situación cuando escribe frases como la siguiente: «Comenzó a decir lo que oirá y verá el que lo oyere o viere el capítulo siguiente [...] que trata de lo que verá el que lo leyere o lo oirá el que lo escuchare leer». O como esta otra: «Leyólas el cura de modo que las oyó Sansón Carrasco, y Sansón y el cura se miraron el uno al otro como admirados de lo que habían leído» (Cervantes, 1998 [1615], cap. 25). La equiparación del significado de «leer» $\mathrm{y}$ «escuchar» transmite claramente la idea de que la lectura se realizaba en voz alta para que otras personas (que no sabían descifrar el significado de los caracteres escritos) pudieran acceder a la historia que se contaba. Siglos después, cuando se extiende la educación y comienza a erradicarse el analfabetismo, la lectura pasa de realizarse habitualmente en voz alta a convertirse en 
un acto silencioso, ya que aumenta significativamente el número de personas que pueden acceder individualmente a los textos escritos.

Actualmente, la lectura en voz alta constituye una excepción que se produce solamente en determinadas situaciones, como pueden ser el discurso de un político, el discurso de un académico o un recital de poesía. No obstante, las piezas líricas se caracterizan por estar basadas en un ritmo y una acentuación que les confiere una musicalidad específica. Por tanto, los efectos sonoros están en la base de la estructura poética y para ser percibidos adecuadamente necesitan de la lectura en voz alta, que, paradójicamente, no se suele practicar en la actualidad. Así lo señalaba Jorge Guillén en 1961:

los poemas no existen más que en la voz y no logran su plenitud sino merced a la lectura de viva voz. Esta realidad del sonido es inseparable de la idea, naturalmente, y la idea no alcanza su propio grado de vigor poético sin su encarnación sonora y sus matices muy precisos (1999 [1961]: 743).

El presente trabajo se sitúa en esta perspectiva y se propone estudiar cómo abordan los poetas la recitación de sus propias obras. Los creadores conciben sus poesías atendiendo al contenido de las mismas y a su forma, que es la cara de la moneda que les proporciona musicalidad y ritmo, sobre todo ritmo, compañero de viaje de los sentimientos que el autor quiere expresar. Los poemas, en numerosos casos, suelen ser recitados por actores que dejan su propia impronta en la oralización, pero en muy pocas ocasiones se ha abordado el análisis del recitado de quienes han concebido el poema. Así, se estudiará a continuación cómo recitan sus poesías tres autores de la misma generación, que eran también amigos entre ellos y, por tanto, conocedores de las mismas tradiciones poéticas: José Agustín Goytisolo, Ángel González y Jaime Gil de Biedma. El análisis realizado se ha basado en las grabaciones de la lectura de sus propios poemas editadas en CD por la editorial Visor. El correspondiente a José Agustín Goytisolo se publicó en 2002, el de Ángel González en 2006 y el de Jaime Gil de Biedma en 2009. Cada CD contiene los poemas más significativos de los tres autores y el material reúne la calidad acústica necesaria para poder ser estudiado mediante los instrumentos informáticos propios de la Fonética experimental.

La discusión sobre si se debe privilegiar el sentido o la forma de un poema cuando se lee en voz alta tiene una larga historia y diversos 
autores se han ocupado de esta cuestión. A título de ejemplo, pueden citarse los trabajos de Navarro Durán (1998), Oliva (2006) o Pardo y Gutiérrez (2011). En este tipo de estudios, en general, se aborda el tema desde la perspectiva de alguien que lee un poema ajeno, un poema del cual no es autor. Pero es interesante preguntarse cómo se realiza la lectura cuando quien lee en voz alta es el propio creador. Belic (2002: 173) señala a este respecto:

Hemos hablado del ejecutante profesional y del privado. Existe, además, un ejecutante privilegiado: el propio autor.Y hay una cosa curiosa: se sabe que grandes poetas como el francés Baudelaire, el ruso Nekrasov, el checo Nezval, el chileno Pablo Neruda, recitaban sus versos de un modo monótono, como una letanía o un salmo. En todo caso parece que lo decisivo era para ellos la entonación. Pablo Neruda, con su modo de recitar, creó en Chile, podría decirse, una escuela de recitación; pero en boca de sus imitadores, su modo de recitar adquirió pronto matices convencionales.

De nuevo Jorge Guillén apunta una respuesta global y generalizadora para esta cuestión:

Cada poeta lee como Dios le da a entender, y este ejercicio vale, por lo menos, como una interpretación digna de tenerse en cuenta. Interpretación de valor relativo, pero con este privilegio: el autor ve la obra a través de su intención (Guillén, 1999 [1961]: 743).

Como es sabido, los juicios de valor formulados sobre la lectura de poemas por sus propios autores han sido, y siguen siendo, en numerosos casos muy negativos. Quienes los formulan parten, de forma implícita o explícita, de su propia concepción de cómo se debe recitar, que viene dictada por las tradiciones y las modas. Guillén, con estas palabras, abre la puerta a otro punto de vista, pues apunta al hecho de que el poeta ve su obra a través de unos ojos distintos de los de un lector que no la ha concebido y no conoce, por tanto, la intención profunda del autor durante la operación de escribir.

En su conocido trabajo "La música de la poesía», señala John Elliot que en el análisis de un poema los recursos semánticos y fónicos constituyen dos caras de la misma moneda (como en la dicotomía saussuriana significado/significante) que no se pueden separar y que deben tomarse en cuenta para apreciar la obra en su totalidad: 
La música de la poesía debe ser una música latente en el lenguaje ordinario de su tiempo. [...] es obligación del poeta usar el lenguaje que oye a su alrededor, aquel con el que está más familiarizado. Siempre recordaré la impresión que me produjo W. B.Yeats leyendo versos en voz alta. Oírle recitar sus propios poemas era reconocer cuánto se necesita de la manera irlandesa de hablar a fin de encontrar y realzar las bellezas de la poesía irlandesa [...]. Por supuesto que no se desea que el poeta reproduzca exactamente el idioma cotidiano suyo, sino que lo que ahí encuentre sea el material con el que haga su poesía. Está obligado, como el escultor, a ser leal al material con que trabaja; con los sonidos que él escucha debe hacer su melodía y su armonía (Elliot, 2009 [1943]: 257).

Carme Riera, en La Escuela de Barcelona (1988), señala algunos de los aspectos del lenguaje poético de la generación de los escritores aquí considerados. Según la autora, sus rasgos más relevantes son el uso de la ironía y la desautomatización de las frases hechas, una intención lúdica en el manejo de la lengua, la colocación de las palabras en contextos distintos a los del uso tradicional y, sobre todo, el hecho de que el lenguaje permeabiliza la realidad hasta conferirle una nueva dimensión. Para la autora, los hechos contados en los poemas son triviales, pero el modo de relatarlos los convierte en originales y se forma así una lengua poética cuya principal característica es el tono conversacional, de forma que el habla coloquial ejerce una gran influencia sobre la palabra escrita y lo dicho en la conversación sirve de punto de partida para lo escrito (Riera, 1988: 109). Su análisis, pues, resalta la importancia que tienen en el significado de las composiciones poéticas las características del lenguaje empleado en las mismas.

Las palabras de Elliot citadas más arriba son especialmente importantes en el contexto del estudio del lenguaje empleado en sus obras por los poetas examinados en este trabajo y, como se ha visto, las observaciones de Riera (1988) van en la misma dirección, pues, formulando con otras palabras la idea del estudioso, puede afirmarse que el lenguaje utilizado por nuestros autores "condiciona» el ritmo y los metros empleados y, también, como se verá más adelante, la forma de recitar.

Belic (2002: 147) apunta en la misma dirección cuando señala: 
Hoy ya nadie niega que el texto poético predetermina la recitación, no solo por la configuración fonética de las palabras que el autor ha elegido, sino también por la extensión de estas (palabras breves, palabras polisílabas), por su matiz semántico (palabras "poéticas», «prosaicas», matizadas emocional e intelectualmente, etc.), por el orden de palabras, por la estructura sintáctica, por la articulación semántica del contexto, etc.

En el prólogo del volumen de José Agustín Goytisolo Palabras para Julia y otras canciones (1980), otro poeta, ManuelVázquez Montalbán, describe de forma totalmente subjetiva la forma de recitar del primero:

José Agustín Goytisolo recitaba sus poemas de perfil. No era el suyo un desplante al flash, porque cuando José Agustín recitaba en las aulas de las universidades lo hacía casi a escondidas, introducido por las puertas traseras, rodeado del recelo de bedeles y decanos [...] José Agustín Goytisolo recitaba sus poemas de perfil en un subrayado corporal perfecto de una poesía desafiante, de una poesía que reclamaba al toro, jeh, toro!, para burlarle en el momento de la embestida o aceptar la evidencia de las declaraciones en sótanos, a media luz, crispado polvo secreto y voces agrias la madrugada en los subterráneos del franquismo.

La cita, a través de esta subjetividad, dice mucho acerca de la importancia de la forma de recitar en la transmisión del significado del poema. La pregunta que se plantea este trabajo es si es posible estudiar objetivamente el conjunto de elementos sonoros que producen un efecto como el que describe Vázquez Montalbán cuando un poeta recita sus composiciones. Los instrumentos de análisis de la Fonética experimental pueden proporcionar datos cuantificables sobre estas cuestiones. Así, desde el punto de vista estrictamente fónico de la sonoridad de los poemas, puede considerarse que los elementos básicos que configuran el recitado son la voz que recita, la forma de pronunciar los sonidos que constituyen el poema y la realización oral de la estructura prosódica y rítmica del mismo. 


\section{LA VOZ QUE RECITA}

Desde diversos ámbitos del estudio del efecto que produce en los demás la voz humana, se observa un amplio consenso en señalar que las voces graves son, en general, las preferidas por los oyentes en la medida en que resultan mucho más agradables al oído que las voces agudas. De forma estrictamente anecdótica cabe señalar el título de un volumen de relatos del escritor Óscar Sipán publicado en 2013: Quisiera tener la voz de Leonard Cohen para pedirte que te marcharas. La voz grave del cantante y poeta fue señalada siempre como una de sus principales cualidades, como puede apreciarse en algunos de los obituarios publicados en diversos medios de comunicación con motivo de su fallecimiento en 2016: «Leonard Cohen, la voz grave de la poesía» (M. Ortale, en El Día, 30-4-2017); «Su voz grave podía ser cálida o abismal, seductora o desgarradora» (en La Opinión de Murcia, 11-11-2016); "Leonard Cohen: el poeta serio y de voz grave» (en RTVE noticias, 11-11-2016); "Con voz grave y alma de poeta, el espíritu de Leonard Cohen revivirá» (La Vanguardia, 21-9-2019); etc. Óscar Sipán apela a esta cualidad de la voz de Cohen y le otorga valor literario: lo que diga una voz de estas características es incontestable.

Desde el ámbito de la Fonética, especialmente del estudio del valor simbólico del sonido, John Ohala (1994) estudia la recepción de la entonación y pone de relieve que existe una estrecha relación entre la forma del patrón entonativo y su función semántica. Ohala parte del hecho de que la mayoría de las lenguas de carácter entonativo utilizan patrones ascendentes hacia las frecuencias agudas para los enunciados interrogativos y patrones descendentes hacia las frecuencias graves para las afirmaciones. En su experimento, el autor, mediante las técnicas propias de la Fonética experimental, manipuló una serie de enunciados de forma que se eliminaron de ellos los sonidos y solamente se podían escuchar las frecuencias graves de los mismos que contienen el patrón melódico, es decir, las oscilaciones ascendentes y descendentes de la entonación. A continuación realizó una encuesta a una serie de informantes a los que, después de escuchar los estímulos manipulados, se les preguntó cuáles les parecían más «dominantes» o «más seguros de sí mismos». Todas las respuestas coincidieron en el hecho de que una entonación grave produce el efecto de mayor seguridad y dominancia, por lo que este fenómeno puede relacionarse con las características de los patrones entonativos 
afirmativos, descendentes hacia las frecuencias graves, e interrogativos, ascendentes hacia las frecuencias agudas (Ohala, 1994: 325).

En otro ámbito de estudio de la voz, el de la fonética forense, Petisco y López (2014) recogen un trabajo de Rodero (2001) en el que la autora indica que el tono de voz grave resulta una cualidad determinante para que la voz de un hombre agrade, de forma que la voz grave masculina suele asociarse a perfiles físicos y psicológicos positivos: mayor belleza, heroicidad, galantería, seguridad, etc. Otros autores como Cyr (2005) señalan que, cuando una persona está excitada sexualmente, su voz se hace más grave y que los seductores utilizan deliberadamente una voz más grave para simular y suscitar deseo.

Finalmente, y volviendo al ámbito de la Literatura, es interesante aportar el ejemplo del cuento de Carme Riera «As you like, Darling», que forma parte del volumen Epitelis tendríssims (1981), en el que una mujer se enamora de un hombre exclusivamente por su voz y todo acaba cuando él queda afónico y ya no puede hablar con ella mientras hacen el amor.

La Fonética experimental ha mostrado que la cualidad de grave o aguda de una voz determinada puede cuantificarse a partir de los valores de frecuencia de su armónico denominado «fundamental». El sonido de la voz humana es una onda sonora periódica compleja, es decir, constituida por numerosas ondas simples. La onda básica o «fundamental» es la producida directamente por las cuerdas vocales y su frecuencia depende de las características fisiológicas individuales. El resto de las ondas sonoras simples que integran la onda sonora de la voz humana presentan una frecuencia que siempre es múltiplo de la frecuencia de la onda fundamental. Así, por ejemplo, una voz masculina suele poseer un «fundamental» que se sitúa alrededor de los $100 \mathrm{~Hz}$, la frecuencia de la siguiente onda simple de dicha voz es de $200 \mathrm{~Hz}$, la siguiente de $300 \mathrm{~Hz}$ y así sucesivamente. Otra voz masculina cuya frecuencia fundamental sea de $110 \mathrm{~Hz}$ incluirá una onda simple de $220 \mathrm{~Hz}$, una tercera de $330 \mathrm{~Hz}$, etc. El estudio de los valores de la frecuencia «fundamental» de las voces de los poetas estudiados, obtenida mediante su análisis con el programa PRAAT (Boersma y Weenink, 2002) a partir de las grabaciones analizadas, muestra que el valor medio de la frecuencia fundamental de la voz de Jaime Gil de Biedma se sitúa en los 111,4 Hz, el de Ángel González en 108,36 Hz y el de José Agustín Goytisolo en los 103,87 Hz. La 
voz más grave, por tanto, es la de este último poeta y este carácter conduciría a afirmar que se trata de la «mejor» percibida por los oyentes, la que despertaría en ellos reacciones más fuertes en relación con el contenido de los poemas recitados. Una investigación interesante y todavía no realizada consistiría en analizar, mediante encuestas de carácter perceptivo similares a las realizadas en el trabajo mencionado de Ohala (1994), si esta hipótesis que, como se ha visto, está presente en el ámbito de la radiofonía, de la fonética simbólica, de la fonética forense y de la literatura tiene una base empírica y si estos efectos tienen carácter universal.

\section{LA PRONUNCIACIÓN DE LOS SONIDOS}

Como se ha señalado en la introducción, John Elliot (2009 [1943]) apuntaba la estrecha relación que une la producción poética de un autor con las características del lenguaje de su época, y una de las características de los poetas de la generación de José Agustín Goytisolo, como subraya Carme Riera (1988 y 1991), es la incorporación del lenguaje coloquial a su poesía. A este respecto, Frau estudia distintos modelos de ejecución versal por parte de varios poetas y observa:

Hay formas de recitado monótonas, monocordes, que no significan nada, pero otras veces la elección de un estilo de lectura por parte del poeta resulta, además, estar en estrecha conexión con su poética. Las de Jaime Gil de Biedma o José Hierro, por ejemplo, tienden a la apariencia conversacional, pero otras, como la de León Felipe, en ocasiones adquieren un marcado dramatismo o apasionamiento, y cada una de ellas parece defender una determinada idea del poeta y la poesía. Es verdad que también hay un cierto aire de época en las formas recitativas, y que versos que hoy ya no podrían escribirse sin parecer arcaicos aparecen unidos, a veces, a voces y acentos de otro tiempo, proclives al engolamiento o a la voz hueca (2017: 21).

Es interesante señalar también que Frau distingue entre diversas formas o estilos de ejecución o recitado por parte de los propios autores y que insinúa que las características de los versos conducen, en muchas ocasiones, a una recitación engolada o al empleo de una voz hueca. Pero lo más destacable de la cita es la afirmación de que Jaime 
Gil de Biedma o José Hierro tienden a la apariencia conversacional cuando recitan. Ello debe relacionarse con las características de su poesía, pues se trata de autores que incorporan el registro coloquial y, por tanto, no parece posible declamar sus poemas, puesto que el lenguaje empleado en ellos no es proclive al engolamiento ni a la declamación.

Lo que, en cambio, no señala Frau (2017) ni tampoco otros autores que estudian el recitado (por ejemplo, Chavez, 2010 o Torre, 2003 y 2016) es la importancia que tiene en él la pronunciación de los sonidos, y se centran casi exclusivamente en los aspectos relacionados con las pausas entre versos, la entonación, el ritmo y los encabalgamientos. El engolamiento y la declamación o, por el contrario, la tendencia a utilizar un registro coloquial tienen una influencia directa sobre la forma de pronunciar cada uno de los sonidos de un poema. La «apariencia conversacional» que señala Frau en la forma de recitar de Gil de Biedma afecta también, por tanto, a la pronunciación de los sonidos, pues comporta una relajación en la pronunciación, imposible en la declamación, que hace aflorar en el recitado fenómenos que afectan a los sonidos y que son propios de la conversación coloquial.

En el caso de Gil de Biedma y en el corpus analizado en este trabajo pueden escucharse numerosos fenómenos que acercan la recitación del autor al lenguaje coloquial cotidiano. La lectura del poeta es rápida, lo que conduce a producir la impresión de lenguaje coloquial, y en «Conversaciones poéticas» aparecen tres ejemplos significativos:

- en el verso 9, en el sintagma «nos recibieron» se produce la elisión de la consonante final de «nos», de forma que el poeta pronuncia [nore $\theta i$ 'ßjeron];

- en el verso 11, el sintagma «después de un viaje» es realizado como [des'pwezdum'bjaxe], con elisión de la vocal de la preposición «de», como suele realizarse en el lenguaje coloquial con la consiguiente resilabación que dicha elisión acarrea;

- en el verso 35, el sintagma "pinos en el atardecer» se pronuncia ['pinosenlatarðe' $\theta \mathrm{er}]$, con elisión de la vocal en el artículo «el»y, como en el ejemplo anterior, con la consiguiente resilabación del sintagma. 
Curiosamente, no es este el caso de Ángel González, quien, si bien tampoco declama, pues su poesía no es apta para este modelo de ejecución, se caracteriza por evitar los fenómenos de reducción y elisión que se han visto en Gil de Biedma hasta el punto de evitar los contactos entre consonantes que pueden conducir a la resilabación. Así, por ejemplo, en el poema «Apoyas la mano» pueden señalarse los siguientes ejemplos:

- en el verso 2, la expresión «las hormigas» se realiza [las/or'miyas], con una brevísima pausa entre las dos palabras;

- en el verso 5, el sintagma "es dulce tu mano» se pronuncia [es/'dulOetu'mano], de nuevo con una brevísima pausa entre el verbo y el complemento, lo cual, además, conduce a que no se sonorice la consonante fricativa [s], como ocurre habitualmente en español cuando dicho sonido se encuentra ante una consonante sonora;

- en el verso 8, la expresión «raíz honda» se realiza [rai $\theta /$ onda], con la misma tendencia a la realización de pausa y con una fuerte marca acentual sobre la vocal [o];

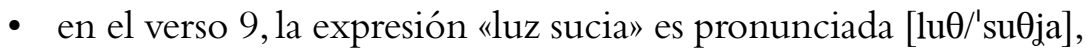
igual que en los casos anteriores;

- y, finalmente, en el verso 12 , la expresión «más sola» se realiza [mas/'sola], es decir, se escuchan claramente dos realizaciones de [s] y no el fenómeno de geminación de dicho sonido que suele producirse en español en contextos como este.

Dos poetas, pues, de la misma generación, pero que adoptan estrategias diferentes cuando se trata de recitar sus creaciones. El caso de José Agustín Goytisolo es mucho más complejo por el tipo de fenómenos que presenta en sus realizaciones de los sonidos del español.

En primer lugar, debe señalarse, en su recitación, la presencia de consonantes labiodentales sonoras [v], inexistentes en español, como en los casos siguientes:

- el verso 8 del poema «La ternura última» dice: «por él vela, por él». La pronunciación del poeta es la siguiente: [porel'vela/por'el]. En español, las grafias «b» $\mathrm{y}$ «V» representan el mismo sonido: [b] o [ß] en posición intervocálica. En cambio, Goytisolo realiza una consonante fricativa labiodental sonora [v] en lugar de una oclusiva $[\mathrm{b}]$ o una aproximante bilabial sonora $[\beta]$; 
- en el verso 12 de «Temporada en Barcelona», que reza «tomo un vodka con hielo», aparece el mismo fenómeno: ['tomown'vodkakon'jelo]. De nuevo, la palabra «vodka», que contiene la grafia «V», es pronunciada con fricativa labiodental sonora;

- y en el poema «No sirves para nada», en el verso 31, la frase «ahora vivo con ella» es realizada [aora'vivo/kon'eja], donde, como puede verse, el fenómeno aparece en dos ocasiones en la palabra «vivo».

Es dificil explicar la presencia de esta consonante en la pronunciación del poeta. Tal vez pudiera ser una reminiscencia de la época de escolarización de José Agustín Goytisolo durante la que, para que los niños no confundieran las grafias «b» $\mathrm{y}$ «V» cuando aprendían ortografia, los profesores se esmeraban en pronunciar las palabras en las que aparecía la segunda de ellas utilizando la consonante fricativa labiodental sonora. En el habla real los hablantes no lo hacían así, pero era un «truco» empleado por muchos profesores para ayudar a los alumnos en su proceso de aprendizaje.

Otro fenómeno interesante en el habla de Goytisolo es la presencia de consonantes fricativas interdentales sordas en posición final de silaba, como en los siguientes casos:

- en el verso 1 de «Temporada en Barcelona», que dice «las gentes de esta bendita ciudad», se escucha [las'xentes/de ${ }^{1}$ estaßen'dita $\theta$ iw'ða $\theta$, con una clara consonante fricativa interdental sorda en posición final;

- en el poema «Era como la luna», en el verso 9, aparece el sintagma «ansiedad y gracia». La pronunciación del poeta es

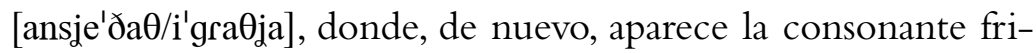
cativa interdental en posición final;

- igual ocurre en el verso 30 de "Temporada de verano», donde el enunciado «que me ofrecen su amistad» es realizado

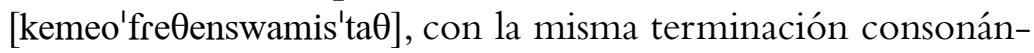
tica que en los casos anteriores;

- finalmente, en el poema «La mejor escuela», puede escucharse en el verso 11 el sintagma «la realidad y la utopía» pronunciado del siguiente modo: [lareali'ðaOilauto'pia].

Parece esta una pronunciación muy curiosa por parte de José Agustín Goytisolo, pues las realizaciones de estas características aparecen, en el dominio geográfico del español, en variedades de la lengua 
muy alejadas de la del poeta. Tal vez pueda insinuarse, no obstante, una explicación que se relaciona también con otro fenómeno que se comentará a continuación. Goytisolo era bilingüe español-catalán y lo era en una época en la que presentar marcas de una lengua cuando se hablaba otra estaba estigmatizado, especialmente si esas marcas procedían de la lengua propia del ámbito más familiar y se hacían notorias en la lengua de cultura. Se debe también tener presente que el poeta escribió básicamente en español, aunque realizó algunas traducciones al catalán y se interesó mucho por la difusión de la poesía en esta lengua (Cotoner, 2007). Algunos rasgos del catalán, como se verá, aparecen claramente en la forma de hablar español de Goytisolo, de manera que la aparición de consonantes fricativas interdentales sordas en posición final podría, tal vez, explicarse como una suerte de hipercorrección por parte del escritor, que tenía clara conciencia de que un hablante monolingüe español no diría nunca [ $\theta$ iw'ðat], [ans'e'ðat], [amis'tat] o [reali'ðat], como lo hacen los bilingües español-catalán. Así, procurando que su español «sonara» como el de un hablante monolingüe podría haber adoptado la solución de la interdental fricativa sorda, puesto que, además, es la más alejada de la pronunciación del español en Cataluña.

Una de principales características del habla de los bilingües español-catalán cuando se expresan en español es la presencia de consonantes fricativas alveolares sonoras $[\mathrm{z}]$ en posición intervocálica. Así, pueden encontrarse ejemplos como los siguientes en la recitación de José Agustín Goytisolo:

- en el poema «La mejor escuela», la expresión «situaciones e imágenes», que se encuentra en el verso 9, es realizada así:

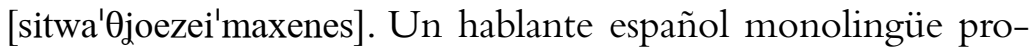
nunciaría [sitwa'Ojoesei'maxenes], es decir, la fricativa alveolar no se sonoriza entre vocales en dicha lengua, solamente se da la sonorización cuando esta consonante está seguida por otra consonante sonora. En cambio, en catalán, la fricativa alveolar sonora no tiene la categoría de alófono, sino de fonema y, por tanto, posee valor distintivo en cuanto al significado, de forma que es una realidad para los catalanohablantes mientras que no ocurre así en el caso de los hispanohablantes monolingües. De ahí, la tendencia espontánea de los hablantes bilingües a pronunciar, en español, un alófono sonoro en las mismas posiciones en las que esta unidad aparece en catalán; 
- el sintagma «reparaciones y humo», que forma parte del título del poema "Buganvillas, reparaciones y humo», es realizado así: [repara'Ojonezi'umo]. De nuevo se observa la presencia de [z] intervocálica;

- la expresión "crecidas sus amigas» que aparece en el verso 16 del poema «Katheleen» presenta la siguiente realización:

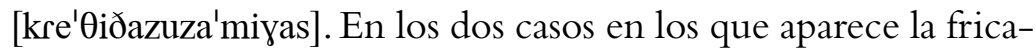
tiva alveolar, la pronunciación que se escucha es sonora;

- finalmente, en el verso 9 del poema «A veces verso», la expresión «encuentras en las páginas» se pronuncia [en'kwetrazenlas'paxinas], de nuevo con la pronunciación correspondiente a la fricativa alveolar sonora.

Las realizaciones de los sonidos vocálicos de José Agustín Goytisolo presentan especial interés desde el punto de vista de su perfil lingüístico bilingüe, pues, ya auditivamente, se percibe en su recitación la presencia de realizaciones de los fonemas /e/ y /o/ con grados de abertura más propios del catalán que del español. Este fenómeno de las diferencias en la abertura de las vocales se explica porque el español, que posee cinco unidades vocálicas, distribuye las realizaciones de las mismas de una forma equilibrada en el espacio vocálico. Puede verse a continuación una carta de formantes de un hablante monolingüe de español en la que se aprecia dicha distribución equilibrada de esta clase de sonidos:

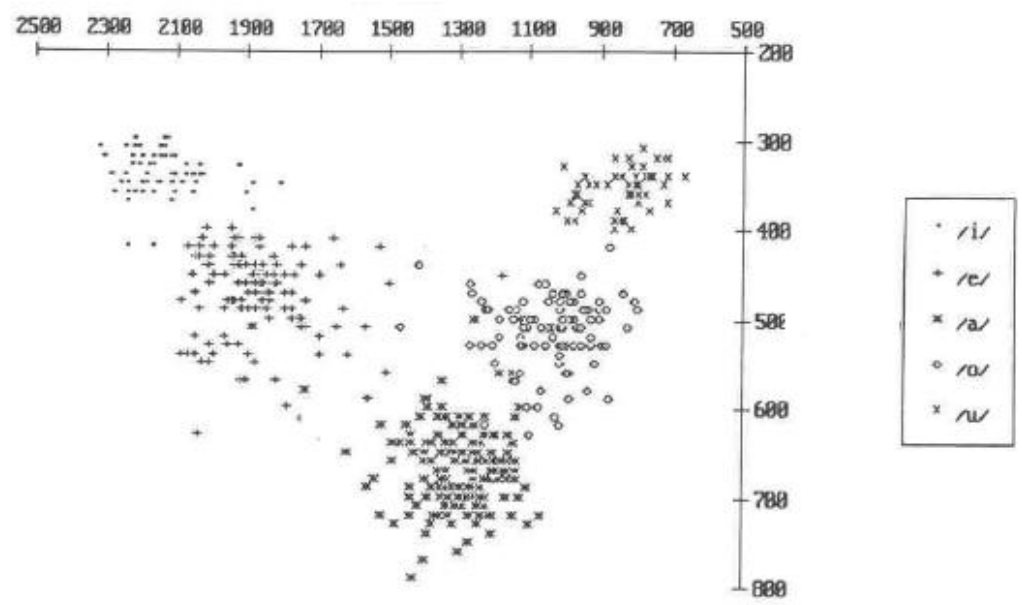

Figura 1: Distribución de las vocales del español realizadas por un hablante monolingüe (Harmegnies y Poch Olivé, 1992). 
Las realizaciones de las vocales /e y /o/ se encuentran en un espacio equidistante del resto de las vocales, y el conjunto del espacio vocálico presenta un equilibrio que engloba todos los elementos que lo componen.

En la Figura 2 pueden verse las realizaciones de las vocales del español realizadas por un hablante bilingüe español-catalán:

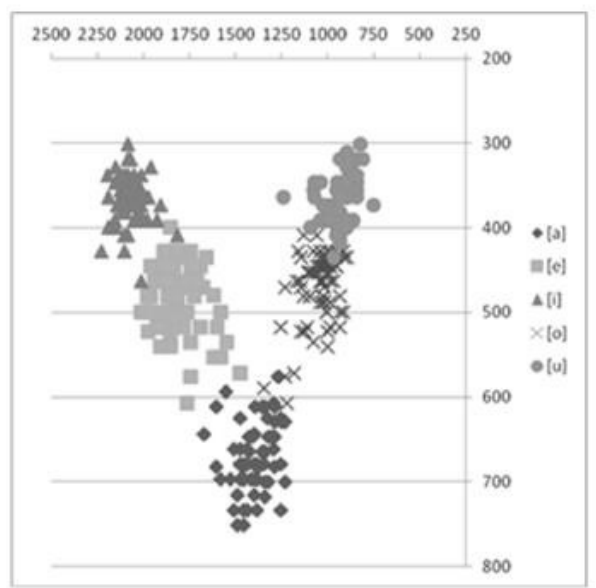

Figura 2: Distribución de las vocales del español realizadas por un hablante bilingüe español-catalán (Machuca y Poch Olivé, 2016).

Como puede verse, las áreas ocupadas por las vocales no presentan, en este caso, la regularidad que se aprecia en el hablante monolingüe. Especialmente en los casos de los fonemas /e/ y /o/ se localizan alófonos con grados de abertura muy diferente (sobre todo, algunos son muy abiertos), fenómeno que no se observa en las realizaciones del hablante monolingüe. El sistema del catalán contiene siete unidades vocálicas en el subsistema tónico, por lo que la distribución de esta clase de sonidos que se aprecia en el espacio vocálico cuando el escritor habla español revela la influencia del sistema de la otra lengua del hablante bilingüe.

Un muestreo equilibrado de las vocales pronunciadas por José Agustín Goytisolo durante el recitado de sus poemas arroja el resultado que se puede ver en la Figura 3: 


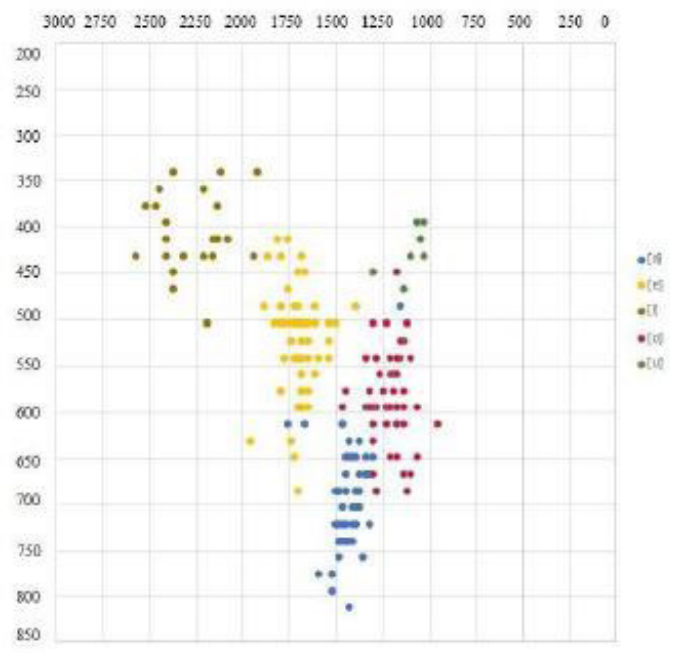

Figura 3: Distribución de las vocales del español realizadas por José Agustín Goytisolo.

Puede apreciarse en el gráfico que la localización de estos sonidos en el espacio vocálico es similar a la que se observa en el hablante bilingüe de la Figura 2, es decir, realizaciones de /e/ y /o/ de abertura muy variable, especialmente algunas muy abiertas, que conducen a pensar que en la pronunciación del español del poeta están también presentes una serie de rasgos que son propios de su otra lengua.

Los datos que se acaban de presentar, referidos a la pronunciación de los sonidos por parte de los poetas durante la operación de recitado, confirman el interés que posee profundizar en el estudio de estos fenómenos. Si bien todos los escritores comparten como característica común que su poesía no admite la declamación, sino que requiere una forma de decir más cercana al habla, presentan diferencias importantes que provocan efectos distintos en el oyente. Jaime Gil de Biedma parece inclinarse por mantener un grado de «coloquialidad» importante en la pronunciación de los sonidos y mantiene la velocidad y, sobre todo, las elisiones propias de la lengua coloquial; en cambio, Ángel González parece buscar la escrupulosidad en la pronunciación dentro de la ligereza que supone huir de la declamación y, finalmente, José Agustín Goytisolo es quien presenta fenómenos más interesantes, pues su perfil de bilingüe emerge en su forma de recitar y le conduce a una forma de pronunciar los 
sonidos del español que produce, sin duda, un efecto muy particular en quien le escucha. Estas diferencias no se pueden formular en términos de juicios de valor sobre una «buena» o una "mala» forma de recitar, pues los poetas son dueños de sus creaciones y ello incluye también su forma de decirlas, en la línea de las reflexiones de Jorge Guillén cuando apunta que el poeta, cuando recita, «ve la obra a través de su intención».

\section{EL RITMO}

Mucho se ha escrito sobre el ritmo en poesía, sobre su función como fundamento básico del poema y sobre sus características, y es imposible resumir aquí los distintos puntos de vista adoptados por los estudiosos de la materia. No obstante, vale la pena recordar las palabras de Octavio Paz (1956) sobre su concepción del ritmo en la poesía:

El período rítmico forma el núcleo del verso y no obedece a la regularidad silábica sino al golpe de los acentos y a la combinación de estos con las cesuras y las sílabas débiles [...] en el verso libre contemporáneo los elementos cuantitativos del metro han cedido el sitio a la unidad rítmica [...]. El ritmo permanece: subsisten las pausas, las aliteraciones, las paranomasisas, el choque de sonidos, la marea verbal. El verso libre es una unidad rítmica y casi siempre se pronuncia de una sola vez $[\ldots]$ por eso, muchas veces es innecesaria la puntuación. Sobran las comas y los puntos: el poema es un flujo y reflujo rítmico de palabras (Paz, 1956: 25-26).

Así caracterizado, el ritmo aparece como un parámetro fundamental, pero, a la vez, inasible en el análisis del poema. No obstante, la Fonética experimental intenta cuantificar el análisis del ritmo, desentrañar sus elementos constitutivos y las relaciones que estos mantienen, puesto que son las que el poeta ha querido introducir en su obra porque son las que producen determinado efecto en el oyente. En la Nueva gramática de la lengua española (RAE, 2011:10.2a y $10.2 \mathrm{k}$ ) se indica que la duración de los sonidos y de las sílabas, su intensidad y el perfil entonativo del verso configuran el ritmo del poema y, por tanto, el ritmo del recitado. Se advierte también que son estos tres parámetros juntos los que organizan el ritmo del poema y 
el ritmo del recitado, pues el efecto que producen es global y su análisis por separado no da cuenta del funcionamiento global del ritmo, que únicamente se puede definir como la sensación producida por la organización y agrupación de los elementos prominentes de un enunciado en intervalos temporales regulares. La Fonética permite, pues, cuantificar separadamente los tres parámetros mencionados, pero para rendir cuenta cabal del ritmo de una composición poética se deben relacionar los datos obtenidos del análisis de cada uno de ellos, ya que esa es la sensación que percibe el oyente.

Se ha analizado en este trabajo, mediante el programa PRAAT, la recitación de cuatro versos endecasílabos por parte de cada uno de los poetas estudiados, con el fin de poder establecer comparaciones entre la duración de las sílabas acentuadas frente a las no acentuadas, entre las oscilaciones de la intensidad y entre las variaciones en el perfil de la curva entonativa. Los versos analizados han sido los siguientes:

\begin{tabular}{|l|}
\hline \multicolumn{1}{|c|}{ Jaime Gil de Biedma } \\
\hline la nostalgia del sol en los terrados \\
\hline que hacía más lejanas nuestras voces \\
\hline amamantando a los remolcadores \\
\hline cuyos contornos son los de tu cuerpo \\
\hline
\end{tabular}

Audio 1: endecasílabos recitados por Jaime Gil de Biedma ${ }^{1}$

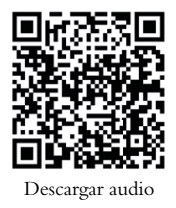

\begin{tabular}{|l|}
\hline \multicolumn{1}{|c|}{ Ángel González } \\
\hline soplo de brisa contra tu mejilla \\
\hline el aire se me vuelve en un suspiro \\
\hline en la pulida mar de tu cadera \\
\hline se me hiela la voz en la garganta \\
\hline
\end{tabular}

Audio 2: endecasílabos recitados por Ángel González ${ }^{2}$

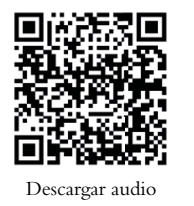

1 Audio 1: https://reunido.uniovi.es/index.php/PREP/article/view/15933/13376

2 Audio 2: https://reunido.uniovi.es/index.php/PREP/article/view/15933/13377 


\begin{tabular}{|l|}
\hline \multicolumn{1}{|c|}{ José Agustín Goytisolo } \\
\hline entonces yo me afeito con cuidado \\
\hline repite mis lecciones de memoria \\
\hline cuando se terminaran las sesiones \\
\hline mas casi siempre bajo tolerancia \\
\hline
\end{tabular}

Audio 3: endecasílabos recitados por José Agustín Goytisolo ${ }^{3}$

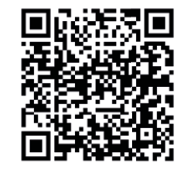

En el Audio 1 puede apreciarse la velocidad a la que recita Jaime Gil de Biedma (ya señalada cuando se han comentado los fenómenos que afectan a la realización de los sonidos). El poeta respeta, y es fácil notarlo, las diferencias de duración entre sílabas acentuadas y no acentuadas, siempre mayor en las primeras. En cuanto a la intensidad, se percibe claramente un descenso generalizado desde el comienzo hasta el final del verso, podría decirse que el ímpetu inicial va disminuyendo progresivamente e igual ocurre con el perfil entonativo que presenta un claro descenso desde el comienzo hasta el final del verso.

En el Audio 2 Ángel González muestra, igual que ocurría con la pronunciación de los sonidos, estrategias diferentes a las de sus colegas. Igual que ellos, González respeta claramente la diferencia de duración entre sílabas acentuadas y no acentuadas. En su caso, la intensidad y la curva de entonación, igual que hacía Gil de Biedma, están sometidas a idénticas oscilaciones desde el comienzo del verso, pero, al llegar al final, se percibe claramente que Ángel González presenta un aumento de la intensidad, mientras que la curva entonativa muestra un descenso (dicho en otras palabras: habla más fuerte, pero su voz se hace más grave). El poeta, pues, parece manejar de forma separada estos dos parámetros, de forma que el oyente percibe un efecto muy diferente del que le producían los endecasílabos recitados por Gil de Biedma.

De nuevo es José Agustín Goytisolo quien presenta características más originales en su manejo de los parámetros que conforman el ritmo. Igual que Gil de Biedma y que González, respeta escrupulosamente la diferencia de duración entre silabas tónicas y sílabas átonas, pero los perfiles de la intensidad y la entonación parecen funcionar, 
en su caso, de forma autónoma. Como puede apreciarse en el Audio 3 , en muchos casos, y durante todo el verso, se percibe claramente que a un descenso o a un aumento de una de ellas le corresponde el movimiento contrario de la otra.

Estos datos ponen de relieve varias cuestiones importantes en el estudio del ritmo. Por una parte, parece confirmarse que dicho parámetro es una sensación de carácter perceptivo que depende de las variaciones cuantitativas de los valores de tres parámetros acústicos que se manifiestan simultáneamente. Además, queda también de manifiesto que, en el recitado, dichos parámetros pueden manejarse de forma independiente por parte de quien «dice» el poema y que el efecto rítmico es el producto de la relación entre ellos. Por otra parte, y como ya se ha insinuado respecto a otros aspectos de la recitación, puede hablarse de la existencia de «estilos» o «modelos» diferentes. Vale la pena insistir de nuevo en el hecho de que lo importante no es realizar una evaluación de las formas de recitar, sino poner de relieve su existencia y mostrar el interés que presenta su estudio.

Además de los tres parámetros estudiados, otros aspectos adquieren también gran importancia en el poema: la frontera versal, los encabalgamientos y, con ellos, el uso de las pausas, y todo ello, además, relacionado con la cuestión de la puntuación, tal como señalaba Octavio Paz. Los tres poetas analizados presentan un comportamiento muy diferente respecto a estos recursos.

En el Audio 4 puede escucharse a Jaime Gil de Biedma recitando su poema «Noches del mes de junio», dedicado a Luis Cernuda:

Alguna vez recuerdo

ciertas noches de junio de aquel año,

casi borrosas, de mi adolescencia

(era en mil novecientos me parece cuarenta y nueve)

porque en ese mes

sentía siempre una inquietud, una angustia pequeña

lo mismo que el calor que empezaba, nada más

que la especial sonoridad del aire y una disposición vagamente afectiva.

Eran las noches incurables y la calentura. 
Las altas horas de estudiante solo

y el libro intempestivo

junto al balcón abierto de par en par (la calle

recién regada desaparecía

abajo, entre el follaje iluminado)

sin un alma que llevar a la boca.

Cuántas veces me acuerdo

de vosotras, lejanas

noches del mes de junio, cuántas veces

me saltaron las lágrimas, las lágrimas

por ser más que un hombre, cuánto quise

morir

o soñé con venderme al diablo, que nunca me escuchó.

Pero también

la vida nos sujeta porque precisamente no es como la esperábamos.

Audio 4: «Noches del mes de junio» recitado por Jaime Gil de Biedma ${ }^{4}$

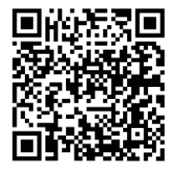

Descargar audio

La lectura de Gil de Biedma, fiel a su apego a lo coloquial, privilegia claramente el sentido del poema y, en ocasiones, parece no tener en cuenta la forma. Como se puede escuchar, muchos encabalgamientos no se notan en la lectura. Tampoco se percibe, en la audición, la disposición de los versos sobre la página: visualmente se aprecia que no todos empiezan alineados al comienzo, sino que algunos presentan un sangrado importante. Si se escucha el poema sin tener ante la vista el texto, no es posible imaginar qué aspecto tiene este poema sobre la página impresa y cabe suponer que, cuando el poeta lo compuso, reflexionó en profundidad sobre la disposición visual de los versos porque añadía matices a la significación global del texto. Un acto de recitación como este podría sugerir que tal vez existan grandes diferencias entre aquello que el poeta tenía en mente al escribir y aquello que transmite cuando recita.

4 Audio 4: https://reunido.uniovi.es/index.php/PREP/article/view/15933/13379 
En el Audio 5, igual que en otras ocasiones, Ángel González muestra unas estrategias completamente distintas:

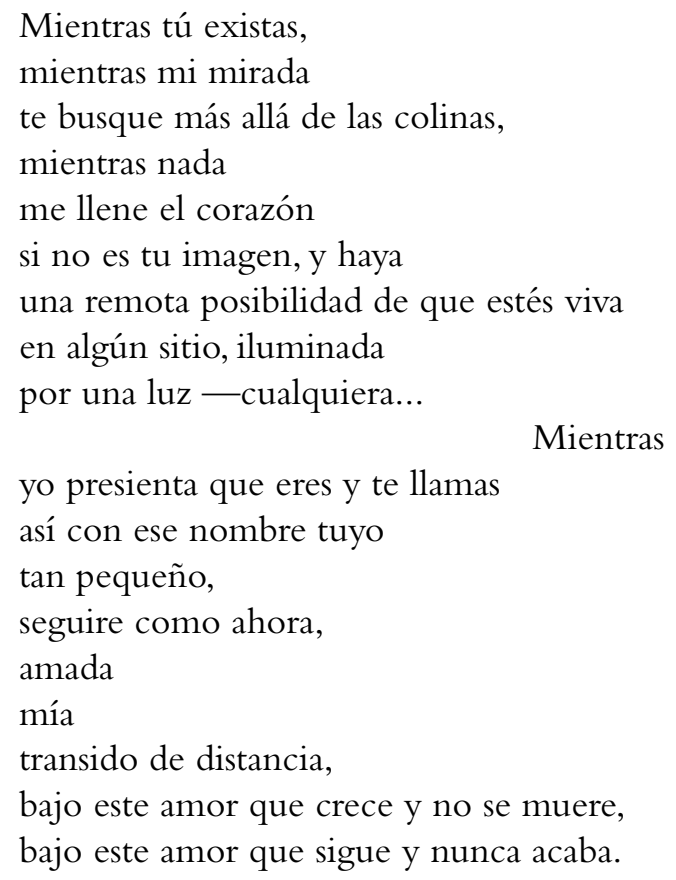

Audio 5: «Mientras tu existas» recitado por Ángel González

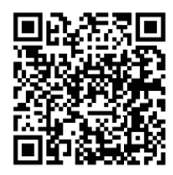

Descargar audio

El poeta respeta el «pentagrama» que construyó mentalmente cuando escribió el poema y, por tanto, la estructura formal del mismo (finales de verso, versos más breves y más largos) se percibe claramente cuando se le escucha recitar.Y se percibe también claramente que ha desarrollado estrategias para respetar la estructura versal, pues, en ocasiones, resuelve los encabalgamientos realizando breves pausas, de una duración mínima pero audible, entre dos versos que, a partir del texto escrito, presentan encabalgamientos. En otras ocasiones, alarga la última sílaba del verso produciendo después una breve pausa que conduce al lector a percibir la frontera en la estructura versal. Diríase que González ha reflexionado sobre las estrategias de recitado (como se ha visto también cuando se ha 
analizado la recitación de sus endecasílabos) de forma que reflejen perfectamente su concepción del poema.

De los tres autores estudiados, José Agustín Goytisolo es el único que escribe sin utilizar la puntuación (recuérdense, de nuevo, las palabras de Octavio Paz al respecto). En el Audio 6 puede escucharse al poeta recitando «La mejor escuela»:

Desconfia de aquellos que te enseñan

listas de nombres

fórmulas

y fechas

y que siempre repiten modelos de cultura

que son la triste herencia que aborreces.

No aprendas solo cosas

piensa en ellas

y construye a tu antojo situaciones e imágenes

que rompan la barrera que aseguran que existe

entre la realidad y la utopía:

Vive en un mundo cóncavo y vacío

juzga cómo sería una selva quemada

detén el oleaje en las rompientes

tiñe de rojo el mar

sigue a unas paralelas hasta que te devuelvan

el punto de partida

coloca el horizonte en vertical

haz aullar a un desierto

familiarízate con la locura.

Después sal a la calle y observa:

es la mejor escuela de tu vida.

Audio 6: «La mejor escuela» recitado por José Agustín Goytisolo

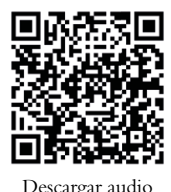

Descargar audio

Como se aprecia en el audio, José Agustín Goytisolo destaca, en su lectura, aquello que él considera conveniente en relación con el significado del poema. Así, realiza pausas donde estima oportuno

6 Audio 6: https://reunido.uniovi.es/index.php/PREP/article/view/15933/13381 
hacerlas, emplea acentos enfáticos para subrayar algún aspecto del sentido y no parece, como en el caso de Gil de Biedma, que la disposición del poema tenga para él ninguna influencia sobre el recitado. La ausencia de puntuación facilita este tipo de interpretaciones en la recitación y permite una total libertad para decidir en qué lugar introducir marcas fónicas que puedan conducir a matizaciones en el significado que, probablemente, pueden variar cada vez que se recita la composición.

Una vez más, queda de manifiesto que cada uno de los poetas estudiados posee sus propias estrategias de recitación, que, también en el caso del empleo de pausas y del tratamiento de los encabalgamientos, conducen a que la mente del oyente perciba un ritmo especial.

\section{CONCLUSIONES}

El análisis de las formas de recitar sus propias obras por parte de los tres poetas considerados en este trabajo ha puesto de manifiesto algo que se ha subrayado ya a lo largo del texto: no es posible realizar juicios de valor, en forma de «bien» o «mal», sobre las estrategias empleadas por cada uno de los autores ante sus creaciones. Los poetas utilizan recursos diferentes cuando recitan y ello conduce a producir efectos diferentes en el oyente. Por otra parte, los poetas son los «dueños» de sus creaciones y, probablemente, cuando recitan tienen en mente cuáles eran sus intenciones en el momento de la escritura. Los juicios de valor reflejan que, quien los emite, tiene su propia idea formada sobre cómo debe ser la recitación y existen opiniones muy diferentes al respecto. Sería de gran interés estudiar la relación existente entre las valoraciones y el modelo mental de quien las realiza, porque ello mostraría las características de diferentes representaciones mentales ante el acto de recitación.

Como se ha podido observar, cada uno de los autores estudiados ha mostrado que recita sus propios poemas de forma diferente a como lo hacen los demás y cada uno de ellos ha utilizado estrategias diferentes. La impresión que producen en el oyente es diferente y revela la relación personalísima existente entre sus creaciones y su forma de decirlas. 
Otra reflexión interesante que se desprende de los resultados hallados en este trabajo es el hecho de que disciplinas como la Fonética experimental, que permiten cuantificar los valores de los diferentes parámetros constitutivos de las ondas sonoras emitidas por los hablantes, al comunicarse o al recitar, permiten también cuantificar la variación de dichos parámetros. Es decir, es posible establecer cuán grave o aguda es la voz de quien dice el poema, es posible analizar la pronunciación de los sonidos que integran la obra lírica y detectar la presencia de fenómenos que son más propios del habla coloquial o de otro tipo de registros más formales.Y es también posible estudiar cómo evolucionan la intensidad, la entonación, las pausas, etc. y establecer, de esta forma, la interacción existente entre los diferentes elementos que constituyen el ritmo. Así, este trabajo se propone también constituir una propuesta metodológica para el estudio objetivo de estos aspectos del poema.

Para terminar, vale la pena recoger, de nuevo, unas palabras de Octavio Paz sobre la relación entre la respiración y el ritmo en el poema, pues el análisis de la recitación de los poetas ha consistido también en intentar estudiar de manera objetiva la relación entre su respiración y sus palabras:

Respirar bien, plena, profundamente, no es solo una práctica de higiene ni un deporte, sino una manera de unirnos al mundo y participar en el ritmo universal. Recitar versos es como danzar con el movimiento general de nuestro cuerpo y de la naturaleza [...]. Recitar fue y sigue siendo un rito. Aspiramos y respiramos el mundo, con el mundo, en un acto que es ejercicio respiratorio, ritmo, imagen y sentido en unidad inseparable. Respirar es un acto poético porque es un acto de comunión. En ella, y no en la fisiología, reside lo que Etiemble llama el "placer poético». [...] Como en el caso del corredor de obstáculos, el recitador salta de palabra en palabra y el placer que se extrae de esta carrera, hecha de vueltas y saltos en un laberinto que irrita y adula los sentidos, no es de género distinto al del luchador o al del nadador. Todo lo dicho antes sobre la poesía como respiración es aplicable a estas ideas: el ritmo no es sonido aislado, ni mera significación, ni placer muscular sino todo junto, en unidad indisoluble (1956: 113). 


\section{BIBLIOGRAFÍA}

BeLIC, Oldrich (2000). Verso español y verso europeo. Introducción a la teoría del verso español en el contexto europeo, Bogotá, Instituto Caro y Cuervo.

Boersma, Paul y David Weenink (2002). Praat: Doing phonetics by computer (Versión 6.1.09) [programa informático], University of Amsterdam, http://www.praat.org.

Cervantes, Miguel de (1998 [1615]). El ingenioso hidalgo don Quijote de la Mancha, ed. Francisco Rico, Barcelona, Crítica.

Chavez, Gloriamarys (2010). Análisis fonoestilístico del poema "Eternidad», de Dulce María Loynaz, Trabajo de Diploma, Universidad Central «Marta Abreu» de Las Villas (Santa Clara, Cuba), http://dspace.uclv.edu.cu/handle/123456789/858.

Cotoner, Luisa (2007). «La colección Marca Hispánica, un ambicioso proyecto de traducción de José Agustín Goytisolo», Quaderns. Revista de Traducció, 14, pp. 105-124.

Elliot, John (2009 [1943]). «La música de la poesía», Atenea, 500, II, pp. 251-264.

FraU, Juan (2017). «Los poetas en su voz: modelos de ejecución y ejemplos de ejecución», Rythmica, 15, pp. 13-32.

Frenk, Margit (1997). Entre la voz y el silencio (la lectura en los tiempos de Cervantes), Alcalá de Henares, Centro de Estudios Cervantinos.

Gil de Biedma, Jaime (2010). Antología personal (De viva voz), CD, Madrid,Visor. GonZÁlez, Ángel (2006). A todo amor, CD, Madrid,Visor.

GuiLlÉn, Jorge (1999 [1961]). «Poesía integral», en Obra en prosa, ed. Francisco J. Diaz de Castro, Barcelona, Tusquets, pp. 736-747.

Goytisolo, Jose Agustín (1980). Palabras para Julia y otras canciones, Barcelona, Laia. - (1997). Antología personal (Viajes en el tiempo), CD, Madrid,Visor.

Harmegnies, Bernard y Dolors Poch Olivé (1992). «A study of styleinduced vowel variability: Laboratory versus spontaneous speech in Spanish», Speech Communication, 11, pp. 429-437.

Machuca, María y Dolors Poch Olivé (2016). «Dinámica de las vocales del español en contacto con el catalán», Oralia, 19, pp. 153-176.

Navarro Durán, Rosa (1998).Cómo leer un poema, Barcelona, Planeta.

OHALA, John (1994). «The frequency code underlies the sound symbolic use of voice pitch", en Sound Symbolism, eds. L. Hinton, J. Nichols y J. Ohala, Cambridge University Press, pp. 325-347. 
Oliva, Salvador (2006). Tractat d'elocució, Barcelona, Empúries.

PARdo, Luis Ernesto y Rocío Gutiérrez (2011). «Perspectivas historiográficas de las prácticas de lectura», Revista Interamericana de Bibliotecología, 34, 2, pp. 221-232.

Paz, Octavio (1956). El arco y la lira, México, Fondo de Cultura Económica.

Petisco, José Manuel y Rafael Manuel López (2014). «A veces

la voz dice más que las palabras», Cuadernos de la Guardia Civil.

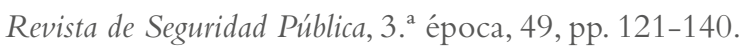

Real ACademia Española (2011). Nueva gramática de la lengua española, vol. 3. Fonética y Fonología, Madrid, Planeta.

_ (2014). Diccionario de la lengua española, Madrid, Planeta.

Riera, Carme (1981). Epitelis tendríssims, Barcelona, Edicions 62.

_- (1988). La Escuela de Barcelona, Barcelona, Anagrama.

- (1991). Hay veneno y jazmín en tu tinta. Aproximación a

la poesía de J. A. Goytisolo, Barcelona, Anthropos.

Rodero, Emma (2001). «El tono de la voz masculina y femenina en los informativos radiofónicos: un análisis comparativo", en Congreso Internacional Mujeres, Hombres y Medios de Comunicación, Valladolid, Junta de Castilla y León, http://www.bocc.ubi.pt/pag/rodero-emma-tono-voz-femenina.pdf.

Sipán, Oscar (2013). Quisiera tener la voz de Leonard Cohen para pedirte que te marcharas, Madrid, Base.

Torre, Esteban (2003). «Fundamentos fonéticos y fonológicos del ritmo», Rhythmica, I, 1, pp. 273-301.

_ (2016). «El soneto "Basta" de Blas de Otero: ritmo y gramática», Rhythmica, XIV, 14, pp. 145-158. 